\title{
Progesterone receptor expression is an independent prognostic variable in early breast cancer: a population-based study
}

\author{
C A Purdie*,1, P Quinlan ${ }^{2}$, L B Jordan ${ }^{1}$, A Ashfield ${ }^{2}$, S Ogston ${ }^{3}$, J A Dewar ${ }^{2}$ and A M Thompson ${ }^{2}$ \\ ${ }^{1}$ Pathology Department, Ninewells Hospital \& Medical School, Dundee DD1 9SY, UK; ${ }^{2}$ Dundee Cancer Centre, University of \\ Dundee, Ninewells Hospital \& Medical School, Dundee DD1 9SY, UK and ${ }^{3}$ Public Health Section, Community Health Sciences \\ University of Dundee, Dundee DD2 4BF, UK
}

Background: Progesterone receptor (PR) expression assessment in early invasive breast cancer remains controversial. This study sought to re-evaluate PR expression as a potential therapeutic guide in early breast cancer; particularly in oestrogen receptor (ER)positive, lymph node (LN)-negative disease.

Methods: A population cohort of 1074 patients presenting to a single Cancer Centre over 4 years (2000-2004) underwent surgery for primary invasive breast cancer with curative intent. Prospective data collection included patient demographics, pathology, ER and PR expression, HER2 status, adjuvant chemotherapy and endocrine therapy. Progesterone receptor expression was compared with (all causes) overall survival (OS), breast cancer-specific survival (BCSS) and disease-free survival (DFS).

Results: Overall survival was $71.0 \%$ and BCSS was $83.0 \%$ at median follow-up of 8.34 years. Absent PR expression was significantly associated with poorer prognosis for OS, BCSS and DFS ( $P<0.0001$, log-rank), even within the ER-positive, LN-negative group (hazard ratio for BCSS 3.17, 95\% Cl 1.43-7.01) and was not influenced by endocrine therapy. Cox's regression analysis demonstrated that PR expression was an independent prognostic variable.

Conclusion: Absence of PR expression is a powerful, independent prognostic variable in operable, primary breast cancer even in ER-positive, LN-negative patients receiving endocrine therapy. Absence of PR expression should be re-evaluated as a biomarker for poor prognosis in ER-positive breast cancer and such patients considered for additional systemic therapy.

Endocrine therapy is well established for early and advanced breast cancer with treatment decisions currently based on the semiquantitative, immunohistochemical assessment of oestrogen receptor (ER) expression on histological material (SIGN, 2007; National Institute for Health and Excellence, 2009; Hammond et al, 2010). In contrast, progesterone receptor (PR) estimation is recommended in some (SIGN, 2007; Hammond et al, 2010), but not all (National Institute for Health and Excellence, 2009) national guidelines.

The role of PR measurement in the management of breast cancer remains controversial. Some commentators suggest that it could be dispensed with (Olivotto et al, 2004) as ER-negative,
PR-positive patients who may respond to endocrine therapy are very rare, limiting its usefulness. However, others consider that, as a prognostic indicator, PR is still worth assessing (MacGrogan et al, 2005).

The potential utility of $\mathrm{PR}$ expression as a prognostic marker has been appreciated since 1975 when it was first suggested that PR expression (by ligand binding assay) could predict outcome and response to ER-directed therapy in advanced disease (Horwitz and McGuire, 1975). This was later confirmed in a prospective study (Ravdin et al, 1992) and in 2004 an immunohistochemical estimation of PR expression was validated and shown to be superior to ligand binding in predicting outcome (Mohsin et al, 2004). 
Progesterone receptor expression predicts response to tamoxifen in premenopausal women and response increases with higher levels of PR expression (Stendahl et al, 2006). In postmenopausal women, the ATAC study (Arimidex, tamoxifen alone, or in combination), using the locally derived hormone receptor expression data, suggested a superior response to aromatase inhibitor (AI) over tamoxifen in patients with ER-positive, PR-negative cancers (Dowsett et al, 2005); a finding not confirmed by other groups studying other AIs (Breast International Group (BIG) 1-98 Collaborative Group et al, 2005; Viale et al, 2007). Subsequent, central ER and PR testing (in the ATAC study patients) also failed to confirm that AIs were superior in ER-positive, PR-negative disease (Dowsett et al, 2008) demonstrating the importance of consistent and quality assured testing. This was further reinforced by the central review of tumour sections in the BIG1-98 and ATAC clinical trials which showed significant discordance between local and central hormone receptor assessment (Viale et al, 2007; Dowsett et al, 2008).

Potential biasing factors in other studies of PR expression in early breast cancer include: PR analysis at multiple, peripheral facilities using different methodologies and patient inclusion/ exclusion criteria (as used in clinical trials). In order to avoid these confounding factors, this study used the preoperative, diagnostic core biopsies (ensuring consistent, rapid fixation and processing) within a single, quality assured and accredited diagnostic pathology service in line with current ASCO/CAP guidelines (Hammond et al, 2010). Furthermore, this study represents a 'real-world' breast cancer population in that every patient presenting to a single regional cancer centre with operable breast cancer over a period of 4 years was included, making it ideal for evaluating PR immunohistochemistry (IHC) for prognosis and treatment planning.

\section{PATIENTS AND METHODS}

Study population. The patient population comprised a consecutive series of all new patients presenting with operable, invasive breast cancer (symptomatic and screen detected) to a single Regional Cancer Centre between 1 July 2000 and 30 June 2004. The Caldicott Guardian granted permission for the use of patient data. The Cancer Centre treats all breast cancer patients from a defined geographic area with all patient records maintained within one institution. All patients undergoing curative surgery were discussed at a multidisciplinary meeting postoperatively and appropriate adjuvant therapy (including chemotherapy) was prescribed as per national guidelines (SIGN, 2007).

Pathology. All pathology was reviewed by a single specialist breast pathologist (CAP) working within an accredited Pathology Laboratory. Data were recorded as per National Guidelines concerning tumour grade, tumour size and LN status (BSP, 2005). The Nottingham Prognostic Index (NPI) was derived from these data (Haybittle et al, 1982). In the 65 patients $(6.1 \%)$ who had multiple tumours and underwent surgery, the cancer with the highest grade was used as the index lesion for the survival analysis.

Hormone receptor expression analysis. Oestrogen receptor and PR analysis were carried out as described (Purdie et al, 2010a). Diagnostic core biopsies were immunostained using primary antibodies for ER (clone 6F11, 1:200) and PR (clone 16, 1:800); both Novocastra Laboratories Ltd, Newcastle Upon Tyne, UK. The stained slides were scored using the 'Quickscore' method (Detre et al, 1995). Cancers scoring $0-3$ were regarded as negative whereas cases scoring 4-18 (maximum) were regarded as positive. Adjuvant endocrine therapy decisions were made on the basis of this assessment. Subsequently, all cancers were further assessed using the ASCO/CAP guidelines (Hammond et al, 2010) for ER and PR expression (1\% cutoff) and also using the 'Allred' method with cases scoring $>2$ defined as positive (Harvey et al, 1999).

HER2 assessment. HER2 assessment by IHC and fluorescent in situ hybridization (FISH) was carried out as described (Purdie et al, 2010a, 2010b) in laboratories accredited by CPA UK Ltd and quality assured by the UK National External Quality Assurance Scheme. All cancers underwent HER2 IHC using the CB11 monoclonal antibody on the diagnostic core biopsy and scored using published criteria (Ellis et al, 2000; Walker et al, 2008). All cancers scoring 'equivocal $(2+)$ ' on IHC were subjected to HER2 FISH analysis carried out using the PathVysion HER2 DNA probe kit (Vysis, Abbott Laboratories, Abbott Park, IL, USA) and assessed by standard criteria (Purdie et al, 2010b). The ratio of orange HER2 signals to green alphasatellite CEP17 signals was calculated and amplification defined as a ratio of $\geqslant 2.00$. Cases scoring IHC-negative $(0)$, IHC-negative $(1+)$ or IHC-equivocal $(2+)$ but FISH-negative were classified as HER2-negative and those scoring IHC equivocal $(2+)$ and FISH-positive or IHCpositive $(3+)$ were regarded as HER2-positive.

Follow-up. Follow-up data were obtained from the Cancer Centre breast oncology database, backed up, where necessary, by contact with the patient's general medical practitioner or the registrar of deaths. Complete follow-up data were obtained for 1072 of the 1074 patients $(99.8 \%)$ who underwent surgery. For patients who died, the date and cause of death was recorded; all deaths not attributable to breast cancer were censored at the date of death. The primary outcome in this analysis was time to breast cancer death; time to death by any cause and time to recurrence (first episode, local and/or distant) were also analysed. Accordingly, the primary end points were overall survival (OS), breast cancerspecific survival (BCSS) and disease-free survival (DFS).

Statistical analysis. Statistical analyses were carried out using SPSS version 20 (IBM, NY, USA). All associations for $2 \times 2$ tables were carried out using a two-sided Fisher's exact test. For $3 \times 2$ tables a chi-squared $\left(\chi^{2}\right)$ test with Yates' correction was employed. Survival analysis was carried out by Kaplan-Meier survival curves analysed by the log-rank test and multivariate analysis was carried out using the Cox regression. Proportional hazards assumptions of the Cox regression analysis were verified using the 'survival' package in $\mathrm{R}$ using the cox.zph procedure (Grambsch and Therneau, 1994).

\section{RESULTS}

Study population. A total of 1283 patients presented with invasive breast cancer (Figure 1). Of these, 209 (16.8\%) did not undergo surgery because of advanced disease or significant comorbidities. The remaining 1074 (84\%) patients had surgical management with curative intent; 328 of whom (30.5\%) were screen detected. Surgery was followed by adjuvant therapy determined by multidisciplinary team discussion with patient choice informed by appropriate guidelines (SIGN, 2007). Chemotherapy was administered to 307 patients $(28.6 \%)$ including 53 who received neo-adjuvant chemotherapy. Endocrine therapy was prescribed to 865 patients $(80.5 \%)$. Of these, 488 received tamoxifen (Tam) only, 35 an AI only, 261 Tam and AI, 47 were part of the BIG 1-98 study (Breast International Group (BIG) 1-98 Collaborative Group et al, 2005) receiving Tam or letrozole and 34 were treated by ovarian suppression.

Pathology. The distribution of tumour grade (15.8\% grade 1, $42.1 \%$ grade 2 and $42.1 \%$ grade 3 ) and nodal status (39.6\% node positive) are what would be expected for a population which was largely symptomatic in presentation (Table 1) (Rakha et al, 2008). Oestrogen receptor-positivity was present in $80.2 \%$ of cancers and 


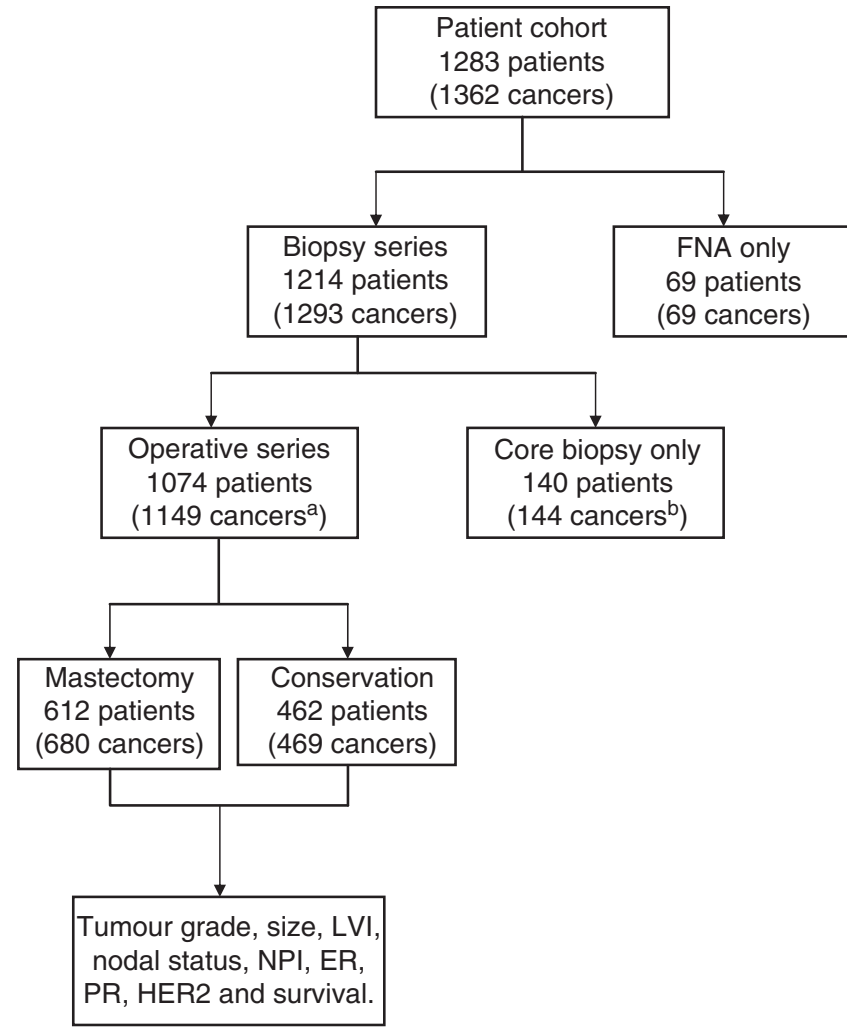

Figure 1. CONSORT diagram of patient and tumour groups. ${ }^{a}$ Fifty-five patients each had two tumours, 10 patients each had three tumours. ${ }^{b}$ Four patients in this group each had two tumours. Abbreviations: $E R=$ oestrogen receptor expression; HER2 = human epidermal growth factor receptor 2 status; $L V I=$ lymphovascular invasion; $\mathrm{NPI}=$ Nottingham Prognostic Index; PR = progesterone receptor expression.

67.2\% were PR-positive. HER2-positivity was detected in $13.9 \%$ (Purdie et al, 2010a). Survival analysis confirmed that tumour grade, tumour size, lymphovascular invasion, LN status and NPI score were all predictive of prognosis in the manner that would be expected (data not shown).

PR expression. PR expression was strongly associated with age, tumour grade, ER expression, NPI group, negative HER2 status and not receiving chemotherapy. There was no significant association between PR expression and nodal status, tumour size, lymphovascular invasion or type of surgery (Table 1). Oestrogen receptor expression was strongly associated with $\mathrm{PR}$ expression and only three cases were ER-negative and PR-positive (0.3\%). The same associations were detected when the Allred score or the ASCO/CAP cutoff (1\%) for ER and PR expression were used (data not shown).

HER2 status. Cancers that were ER-positive, PR-negative were significantly more likely to be HER2-positive (18\%) than those that were ER-positive, PR-positive $(8 \%, P<0 \cdot 001)$ (Table 2).

Survival. Follow-up data for OS, BCSS and DFS were obtained from 1072 patients $(99.8 \%)$. Overall survival was $71.0 \%$ and BCSS $83.0 \%$ at median follow-up of 8.34 years. For all variables where there was a significant association with BCSS, there was a similar, significant association with DFS and hence DFS data are not shown.

Separating the entire cohort of patients into four groups on the basis of ER, PR and HER2 status demonstrated a highly significant difference in BCSS in these groups (Figure 2A). When PR was

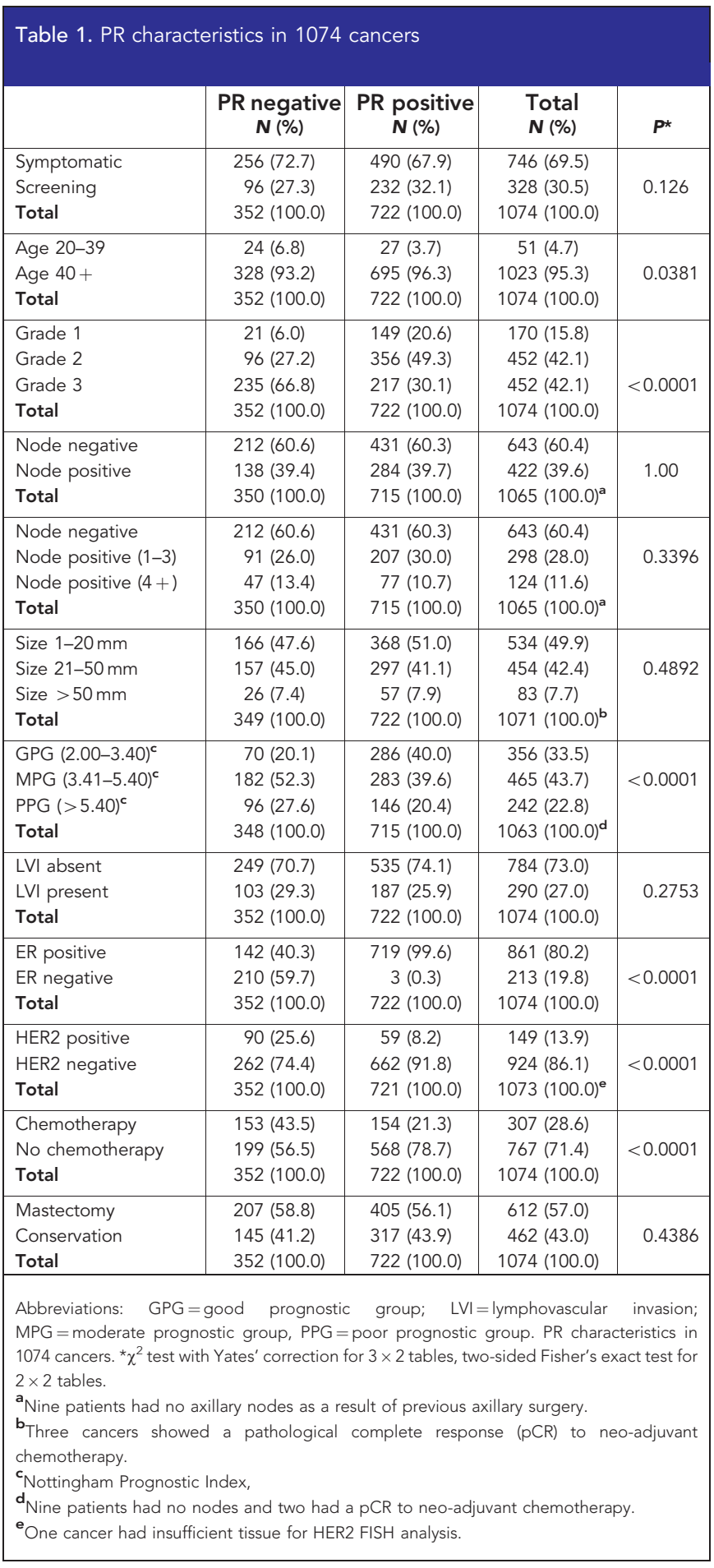

examined as the sole variable for all patients, absence of PR expression was strongly associated with a worse BCSS (HR 3.24, 95\% CI 2.42-4.34, Figure 2B).

Absence of PR expression was associated with poorer prognosis in ER-positive patients treated with any endocrine therapy (Figure 2C). Furthermore, the association of PR-negative tumours with poor prognosis was also seen in both LN-positive $(P<0 \cdot 0001)$ and LN-negative $(P<0 \cdot 0001)$ groups (Figure $3 \mathrm{~A}$ and $\mathrm{B})$ as well as in those patients who did $(P<0 \cdot 0001)$ or did not $(P<0 \cdot 0001)$ receive chemotherapy (Figure $3 \mathrm{C}$ and $\mathrm{D})$. These findings are summarised in Table 3.

Cox regression analysis. Cox regression analysis was carried out using PR expression as well as the standard pathological and 
biomarker variables employed by NPI and Adjuvant! Online in addition to HER2 (Table 4). Progesterone receptor was an independent prognostic variable for both BCSS and DFS in this analysis, and, despite the very close association with ER, PR was a more powerful predictor of BCSS and DFS than ER. Conventional clinical and pathological factors were prognostic in keeping with the literature (Blamey et al, 1979; Haybittle et al, 1982; Mook et al, 2009).

\section{DISCUSSION}

This study is the largest, population-based analysis of $P R$ expression in breast cancer carried out using the current standard of care methodology (Hammond et al, 2010). Although retrospective, it does have the advantage of comprising an unselected, operable breast cancer population without any exclusions or

Table 2. Association of HER2 status with PR expression in ER-positive cancers

\begin{tabular}{|l|c|c|c|c|} 
& PR-negative & PR-positive & \multicolumn{1}{|c|}{ Total } & \\
& $\mathbf{N}(\%)$ & $\mathbf{N}(\%)$ & $\mathbf{N}(\%)$ & $\boldsymbol{P}$-value \\
\hline HER2-negative & $117(82.4)$ & $659(91.8)$ & $776(90.2)$ & \\
HER2-positive & $25(17.6)$ & $59(8.2)$ & $84(9.8)$ & $<0.001$ \\
Total & $142(100.0)$ & $718(100.0)$ & $860(100.0)$ & \\
\hline
\end{tabular}

A

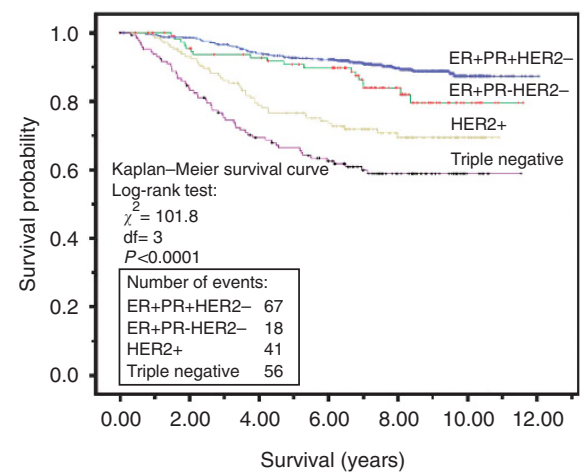

Number at risk:

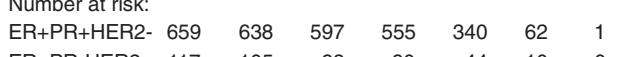

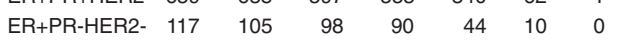

$\begin{array}{llllllll}\text { HER2+ } & 149 & 133 & 108 & 92 & 51 & 17 & 0\end{array}$

$\begin{array}{llllllll}\text { Triple negative } & 145 & 117 & 93 & 78 & 42 & 7 & 0\end{array}$ selection bias. Furthermore, the pathology and biomarker analyses were carried out prospectively in a single, accredited laboratory and represent a 'real-world' assessment of the value of PR expression in clinical practice (Hammond et al, 2010).

Breast cancer gene expression profiling has yielded significant advances in recent years (Sørlie et al, 2001; West et al, 2001; van de Vijver et al, 2002; van t Veer et al, 2002) indicating that ER-positive disease can be divided into luminal A and B sub-types which differ on the basis of the greater expression of proliferation-associated genes in luminal B cancers. Supporting evidence comes from an association between Ki67 proliferation index and gene expression profiling which, in at least one study, allowed the identification of a poorer prognosis (luminal B) subgroup of ER-positive patients (Cheang et al, 2009). However, the method only correctly assigned the tumours to luminal A or B in $75 \%$ of patients reflecting the need for further analysis using validated methods before widespread adoption of Ki67 (Yerushalmi et al, 2010).

It has been suggested that ER-positive, PR-negative cancers belong to the luminal B group (Creighton et al, 2009), implying an overlap between measures of proliferation and absence of PR expression in ERpositive cancers. Much interest has centred on the assessment of cell proliferation by counting cells immunostained for the proliferation marker Ki67 (recently reviewed (Dowsett et al, 2011)). Many studies, using this technique, have shown that Ki67 predicts outcome. Our finding of a significant association of PR-negative subtype with tumour grade (of which mitotic count is a key part (BSP, 2005)) would be consistent with this. Unfortunately, the methodology for Ki67 assessment varies from one study to another with cutoffs ranging from 0 to $30 \%$. As a result, there is, as yet, no accepted diagnostic

C

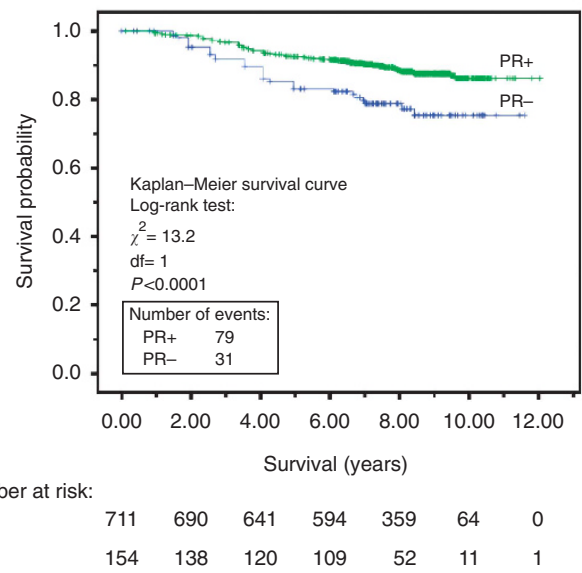

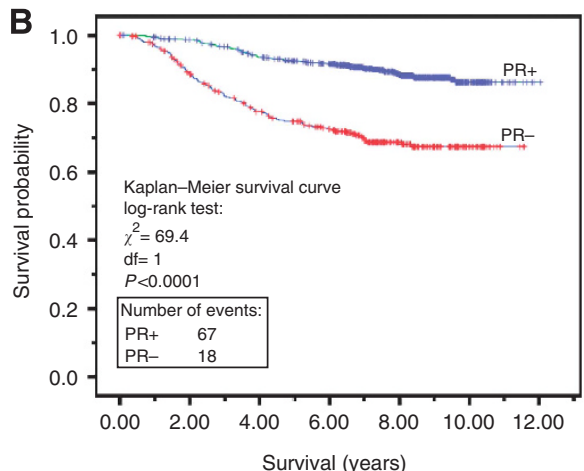

Number at risk:

$\begin{array}{llllllll}\text { PR+ } & 722 & 700 & 650 & 602 & 366 & 69 & 1\end{array}$ $\begin{array}{llllllll}\text { PR- } & 352 & 297 & 250 & 217 & 112 & 27 & 0\end{array}$

Figure 2. Kaplan-Meier plot of BCSS for all patients by: (A) ER, PR and HER2 status, (B) PR status only and (C) PR status in patients who received any endocrine therapy (all were ER-positive). 
A

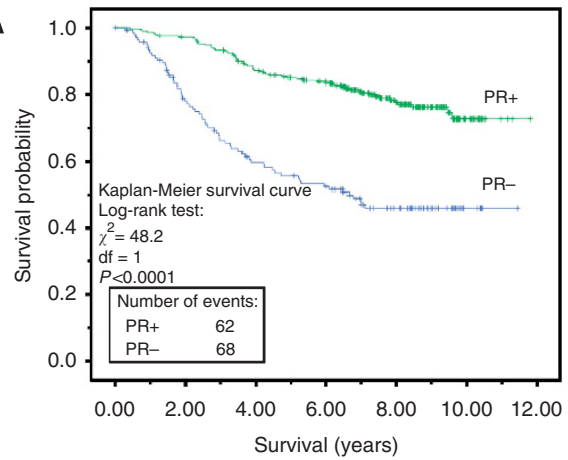

Number at risk:

$\begin{array}{rrrrrrrr}\text { PR+ } & 284 & 274 & 241 & 214 & 120 & 21 & 0 \\ \text { PR- } & 138 & 99 & 74 & 64 & 40 & 7 & 0\end{array}$

C

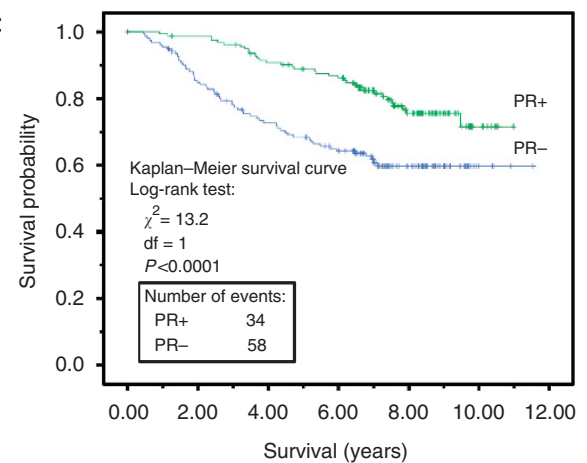

Number at risk:

$\begin{array}{lrrrrrrr}\text { PR+ } & 154 & 151 & 137 & 126 & 66 & 9 & 0 \\ \text { PR- } & 153 & 106 & 106 & 90 & 45 & 4 & 0\end{array}$

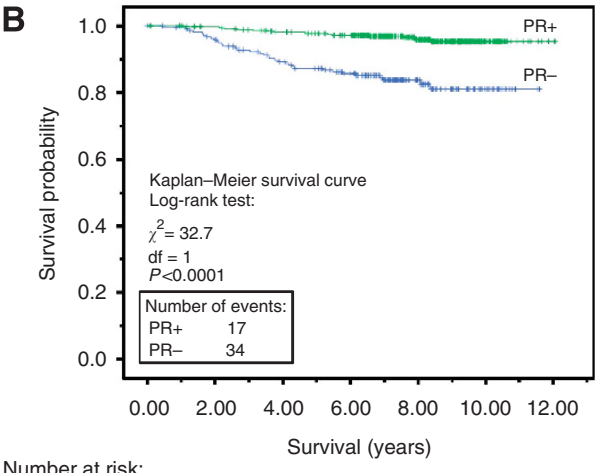

Number at risk:
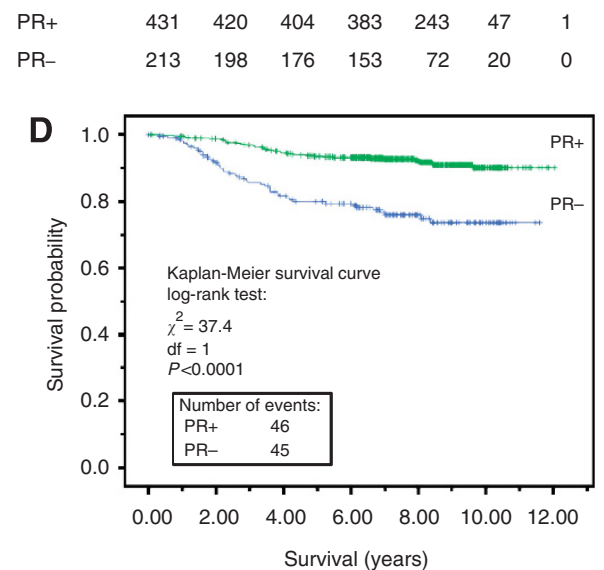

Number at risk:

$\begin{array}{llllllll}\mathrm{PR}+ & 568 & 549 & 513 & 476 & 300 & 60 & 1\end{array}$

$\begin{array}{llllllll}\text { PR- } & 199 & 170 & 144 & 127 & 67 & 23 & 0\end{array}$

Figure 3. Kaplan-Meier plot of BCSS by PR status in: (A) LN-positive patients, (B) LN-negative patients, (C) patients who received chemotherapy and (D) patients who did not receive chemotherapy.

standard for the measurement of Ki67 proliferation fraction and current guidelines suggest that it cannot be generally applied to diagnostic, clinical situations (Dowsett et al, 2011). Progesterone receptor expression, conversely, is internationally used (SIGN, 2007; Hammond et al, 2010), is subject to rigorous quality assurance and has well-defined parameters for assessment as a result of the work carried out to ensure the validity of ER assessment in guiding endocrine therapy. As such, PR expression, rather than Ki67, could be a useful marker to identify a group of ER-positive patients (particularly those who are LN-negative) who have a significantly worse prognosis and might benefit from more aggressive adjuvant therapy.

Intratumoral heterogeneity of PR expression is a significant feature and has been identified in $28.9 \%$ of tumours (Torhorst et al, 2001). Tissue micro-arrays (TMAs) using a single $0.6 \mathrm{~mm}$ diameter core per tumour showed only $88 \%$ concordance with a full section of resected tumour (Torhorst et al, 2001). A single $0.6 \mathrm{~mm}$ core in a TMA has a surface area of $1.13 \mathrm{~mm}^{2}$ for assessment whereas we examined at least two 14-gauge cores giving an area of $68.4 \mathrm{~mm}^{2}$ for examination (more than 60 times that of a TMA core). Even using a larger $(1.0 \mathrm{~mm})$ TMA core gave a concordance of only 67-90\% (Kyndi et al, 2008). Furthermore, many studies use cell counts of 50-100 cells in order to classify a tumour (Kyndi et al, 2008; Faratian et al, 2009); this may not be suitable for PR due to heterogeneity of expression. TMA material may also suffer from inconsistent and sometimes poor fixation and tissue processing; parameters known to adversely affect immunohistochemical scoring (Mann et al, 2005; Hammond et al, 2010). Thus, studies using a single TMA core per tumour to examine PR expression need to be viewed with some caution, as there is a significant risk of false-negative scoring.
Although other studies have examined PR expression in larger cohorts of breast cancer patients, these have either employed TMAs (Liu et al, 2010) or (now obsolete) biochemical assays (Bardou et al, 2003). Our study identified PR expression in $67.2 \%$ whereas studies using the TMA methodology identified PR expression in only 51.2\% (Liu et al, 2010). Current ASCO/CAP guidelines recommend that the diagnostic assessment of ER and PR be carried out on core biopsy material (Hammond et al, 2010); the technique used throughout this study.

ER-negative, PR-positive cancers are exceptionally rare $(0.3 \%)$. This suggests that the assessment of PR expression in ER-negative tumours to identify those that might still benefit from endocrine therapy may not be justified (Olivotto et al, 2004). Progesterone receptor expression correlates with ER expression, negative HER2 status, tumour grade and age at presentation but not with LN status, tumour size or lymphovascular invasion. These data are all in keeping with previous studies (Liu et al, 2010) and indicate that PR-expressing tumours are more common in post-menopausal women with low-grade, ER-positive breast cancers who, generally, have a good prognosis.

Using ER, PR and HER2 can stratify patients into four distinct prognostic groups (Figure 2A). The best prognosis cancers are ER-positive, PR-positive and HER2-negative, whereas the worst prognosis belongs to the triple negative cancers. This stratification of prognosis, using already available biomarkers, persists despite the use of guideline-based adjuvant therapies (but predates the use of trastuzumab in this population) and provides very powerful information to guide treatment planning.

Of note, many of the PR-negative patients recur and/or die from breast cancer in the first 5 years following diagnosis, at a time when 


\begin{tabular}{|c|c|c|c|c|c|}
\hline Subset & PR & $\begin{array}{c}\text { Survival } \\
\text { (\%) }\end{array}$ & $\chi^{2}$ & $\boldsymbol{P}$-value & $\begin{array}{l}\text { Hazard ratio } \\
(95 \% \mathrm{Cl})\end{array}$ \\
\hline \multicolumn{6}{|l|}{ BCSS } \\
\hline All cases & $\begin{array}{l}- \\
+\end{array}$ & $\begin{array}{l}70.7 \\
89.8\end{array}$ & 62.026 & $<0.0001$ & $3.239(2.418-4.340)$ \\
\hline ER+ & $\begin{array}{l}- \\
+\end{array}$ & $\begin{array}{l}83.1 \\
89.0\end{array}$ & 5.885 & 0.015 & $1.761(1.115-2.782)$ \\
\hline $\mathrm{ER}+\mathrm{LN}+$ & $\begin{array}{l}- \\
+\end{array}$ & $\begin{array}{l}68.2 \\
78.1\end{array}$ & 3.987 & 0.046 & $1.806(1.011-3.266)$ \\
\hline $\mathrm{ER}+\mathrm{LN}-$ & $\begin{array}{l}- \\
+\end{array}$ & $\begin{array}{l}89.8 \\
96.3\end{array}$ & 8.130 & 0.004 & $3.170(1.434-7.006)$ \\
\hline ER + Chemo + & $\begin{array}{l}- \\
+\end{array}$ & $\begin{array}{l}62.9 \\
78.4\end{array}$ & 5.924 & 0.015 & $2.226(1.169-4.239)$ \\
\hline ER+ Chemo- & $\begin{array}{l}- \\
+\end{array}$ & $\begin{array}{l}89.7 \\
91.9\end{array}$ & 1.064 & 0.302 & $1.414(0.732-2.731)$ \\
\hline \multicolumn{6}{|l|}{ DFS } \\
\hline All cases & $\begin{array}{l}- \\
+\end{array}$ & $\begin{array}{l}64.5 \\
83.7\end{array}$ & 60.42 & $<0.001$ & $2.719(2.113-3.498)$ \\
\hline ER+ & $\begin{array}{l}- \\
+\end{array}$ & $\begin{array}{l}76.1 \\
83.7\end{array}$ & 7.749 & 0.005 & $1.722(1.174-2.524)$ \\
\hline $\mathrm{ER}+\mathrm{LN}+$ & $\begin{array}{l}- \\
+\end{array}$ & $\begin{array}{l}56.8 \\
70.7\end{array}$ & 5.739 & 0.017 & 1.841 (1.117-3.034) \\
\hline $\mathrm{ER}+\mathrm{LN}-$ & $\begin{array}{l}- \\
+\end{array}$ & $\begin{array}{l}84.7 \\
92.3\end{array}$ & 8.145 & 0.004 & $2.444(1.323-4.515)$ \\
\hline ER + Chemo + & $\begin{array}{l}- \\
+\end{array}$ & $\begin{array}{l}51.4 \\
71.9\end{array}$ & 8.520 & 0.004 & $2.319(1.318-4.078)$ \\
\hline ER + Chemo- & $\begin{array}{l}- \\
+\end{array}$ & $\begin{array}{l}84.1 \\
86.9\end{array}$ & 1.406 & 0.236 & $1.376(0.812-2.333)$ \\
\hline
\end{tabular}

\begin{tabular}{|c|c|c|c|c|c|}
\hline & B & SE & Wald & $\boldsymbol{P}$-value & $\begin{array}{c}\text { Hazard ratio } \\
(95 \% \mathrm{Cl})\end{array}$ \\
\hline \multicolumn{6}{|l|}{ BCSS } \\
\hline $\begin{array}{l}\text { LN status } \\
\text { Size } \\
\text { PR-negative } \\
\text { Grade } \\
\text { ER-negative } \\
\text { HER2-positive }\end{array}$ & $\begin{array}{l}1.177 \\
0.720 \\
0.753 \\
0.413 \\
0.575 \\
0.132\end{array}$ & $\begin{array}{l}0.176 \\
0.125 \\
0.236 \\
0.155 \\
0.246 \\
0.187\end{array}$ & $\begin{array}{r}44.662 \\
33.366 \\
10.154 \\
7.092 \\
5.460 \\
0.496\end{array}$ & $\begin{array}{l}0.000 \\
0.000 \\
0.001 \\
0.008 \\
0.019 \\
0.481\end{array}$ & $\begin{array}{l}3.245(2.298-4.582) \\
2.055(1.609-2.624) \\
2.124(1.336-3.376) \\
1.511(1.115-2.047) \\
1.777(1.097-2.879) \\
1.141(0.791-1.646)\end{array}$ \\
\hline \multicolumn{6}{|l|}{ DFS } \\
\hline $\begin{array}{l}\text { LN status } \\
\text { PR-negative } \\
\text { Size } \\
\text { Grade } \\
\text { ER-negative } \\
\text { HER2-positive }\end{array}$ & $\begin{array}{l}0.935 \\
0.663 \\
0.582 \\
0.390 \\
0.375 \\
0.084\end{array}$ & $\begin{array}{l}0.146 \\
0.197 \\
0.108 \\
0.127 \\
0.211 \\
0.167\end{array}$ & $\begin{array}{r}40.741 \\
11.372 \\
28.818 \\
9.389 \\
3.150 \\
0.255\end{array}$ & $\begin{array}{l}0.000 \\
0.001 \\
0.000 \\
0.002 \\
0.076 \\
0.614\end{array}$ & $\begin{array}{l}2.547(1.911-3.393) \\
1.941(1.320-2.854) \\
1.790(1.447-2.214) \\
1.477(1.151-1.895) \\
1.455(0.962-2.200) \\
1.088(0.785-1.508)\end{array}$ \\
\hline $\begin{array}{l}\text { Abbreviations: } B C \\
\text { receptor; HER2 } \\
\text { PR=progesteron }\end{array}$ & $\begin{array}{l}\text { brest ca } \\
\text { Iman } \\
\text { ceptor. }\end{array}$ & (e) & sed & $\begin{array}{l}\mathrm{FS}=\text { diseas } \\
\text { ctor recep }\end{array}$ & $\begin{array}{l}\text { ree survival; } E R=\text { oestroger } \\
\text { pr 2; } L N=\text { lymph node }\end{array}$ \\
\hline
\end{tabular}

additional adjuvant therapy might be most effective. Unfortunately, anthracycline-based regimes employed within the study period do not appear to have restored the BCSS or DFS for
PR-negative to that of PR-positive (Figure 3C and D). However, PR expression was not used for decision-making regarding the use of chemotherapy during the study. The prognostic significance of PR expression is present within all breast cancer subsets and, furthermore, the deleterious influence of the absence of PR expression (in ER-positive disease) is still evident despite endocrine therapy (Viale et al, 2007; Dowsett et al, 2008).

Multivariate analysis demonstrates that $\mathrm{PR}$ expression is an independent prognostic variable more powerful than ER for predicting BCSS and DFS. For example, in this series, in the ER-positive subgroup, PR expression is second only to LN status in predicting BCSS (all patients in this subgroup received endocrine therapy). Progesterone receptor is, therefore, a powerful, independent predictor of outcome with a hazard ratio (HR) of 3.24 for BCSS and 2.72 for DFS in all patients and 1.76 for BCSS and 1.72 for DFS in the endocrine-treated ER-positive subgroup. Oestrogen receptor-positive, LN-negative patients fall into a good prognostic group and may receive endocrine therapy as their only adjuvant, systemic therapy. However, survival analysis of this group again shows that absence of $\mathrm{PR}$ expression predicts significantly poorer outcome with a HR of 3.17 for BCSS and 2.44 for DFS.

The expression of PR is directly related to oestrogen binding to ERs and the function of PR is dependent on the normal structure and function of ER (Horwitz and McGuire, 1978; Yu et al, 1981). Thus, simplistically, absence of PR expression may simply be a marker of loss of normal ER pathway function that would account for the relative unresponsiveness to endocrine therapy that we have demonstrated in this study. A number of possible mechanisms for the development of ER-positive, PR-negative breast cancers have been postulated including downregulation of PR by crosstalk with the epidermal growth factor receptor pathways (recently reviewed (Thakkar and Mehta, 2011)). Our finding that ER-positive, PR-negative breast cancer is more likely than ER-positive, PR-positive to be HER2-positive (18\% vs $8 \%, P<0.001)$ is consistent with these data (Dowsett et al, 2001; Arpino et al, 2005).

On the basis of an assessment at the time of primary diagnosis, ER-positive, PR-negative breast cancers have a poorer prognosis than ER-positive, PR-positive cancers. We have previously shown that when ER-positive breast cancer recurs, it frequently shows a change from PR-positive to PR-negative (26\%) suggesting that loss of PR expression and the development of hormone therapy unresponsiveness occur with disease progression (Thompson et al, 2010).

The prognostic effect of PR-negativity in the ER-positive, HER2negative group becomes most pronounced beyond 6 years of followup where the survival curves diverge (Figure 2A). This corresponds to the period beyond standard endocrine therapy of 5 years raising the possibility that extended adjuvant endocrine therapy could improve the outcome of these patients. This question might be answered by subgroup analysis in clinical trials of extended adjuvant endocrine therapy such as MA17 (Jin et al, 2012). This finding also emphasises the importance of extended follow-up to identify markers of late relapse, which will become increasingly important as the survival of breast cancer patients improves with better management.

\section{CONCLUSION}

Absence of PR expression in primary breast cancer is strongly and independently associated with worse prognosis and this effect is seen in all subgroups including the ER-positive LN-negative group that usually has a particularly good prognosis. Assessment of PR expression by IHC in breast cancer is already subject to wellestablished and rigorous QA measures. Thus, PR expression could be used to identify patients in, otherwise good prognostic groups, who might benefit from additional adjuvant chemotherapy, extended endocrine therapy and/or treatments targeting growth factor receptor pathways. 


\section{REFERENCES}

Arpino G, Weiss H, Lee A, Schiff R, De Placido S, Osborne C, Elledge R (2005) Estrogen receptor-positive, progesterone receptor-negative breast cancer: association with growth factor receptor expression and tamoxifen resistance. J Natl Cancer Inst 97: 1254-1261.

Bardou V-J, Arpino G, Elledge RM, Osborne CK, Clark GM (2003) Progesterone receptor status significantly improves outcome prediction over estrogen receptor status alone for adjuvant endocrine therapy in two large breast cancer databases. J Clin Oncol 21: 1973-1979.

Blamey R, Davies C, Elston C, Johnson J, Haybittle J, Maynard P (1979) Prognostic factors in breast cancer - the formation of a prognostic index. Clin Oncol 5: 227-236.

Breast International Group (BIG) 1-98 Collaborative GroupThürlimann B, Keshaviah A, Coates AS, Mouridsen H, Mauriac L, Forbes JF, Paridaens R, Castiglione-Gertsch M, Gelber RD, Rabaglio M, Smith I, Wardley A, Wardly A, Price KN, Goldhirsch A (2005) A comparison of letrozole and tamoxifen in postmenopausal women with early breast cancer. N Engl J Med 353: 2747-2757.

BSP (2005) Pathology Reporting of Breast DiseaseNHS BSP: Sheffield 1-144, Publication No 58.

Cheang MCU, Chia SK, Voduc D, Gao D, Leung S, Snider J, Watson M, Davies S, Bernard PS, Parker JS, Perou CM, Ellis MJ, Nielsen TO (2009) Ki67 index, HER2 status, and prognosis of patients with luminal B breast cancer. J Natl Cancer Inst 101: 736-750.

Creighton C, Kent Osborne C, van de Vijver M, Foekens J, Klijn J, Horlings H, Nuyten D, Wang Y, Zhang Y, Chamness G, Hilsenbeck S, Lee A, Schiff R (2009) Molecular profiles of progesterone receptor loss in human breast tumors. Breast Cancer Res Treat 114: 287-299.

Detre S, Saclani Jotti G, Dowsett M (1995) A 'quickscore' method for immunohistochemical semiquantitation: validation for oestrogen receptor in breast carcinomas. J Clin Pathol 48: 876-878.

Dowsett M, Allred C, Knox J, Quinn E, Salter J, Wale C, Cuzick J, Houghton J, Williams N, Mallon E, Bishop H, Ellis I, Larsimont D, Sasano H, Carder P, Cussac A, Knox F, Speirs V, Forbes J, Buzdar A (2008) Relationship between quantitative estrogen and progesterone receptor expression and human epidermal growth factor receptor 2 (HER-2) status with recurrence in the Arimidex, Tamoxifen, Alone or in Combination trial. J Clin Oncol 26: 1059-1065.

Dowsett M, Cuzick J, Wale C, Howell T, Houghton J, Baum M (2005) Retrospective analysis of time to recurrence in the ATAC trial according to hormone receptor status: an hypothesis-generating study. J Clin Oncol 23: 7512-7517.

Dowsett M, Harper-Wynne C, Boeddinghaus I, Salter J, Hills M, Dixon M, Ebbs S, Gui G, Sacks N, Smith I (2001) HER-2 amplification impedes the antiproliferative effects of hormone therapy in estrogen receptor-positive primary breast cancer. Cancer Res 61: 8452-8458.

Dowsett M, Nielsen TO, A'hern R, Bartlett J, Coombes RC, Cuzick J, Ellis M, Henry NL, Hugh JC, Lively T, McShane L, Paik S, Penault-Llorca F, Prudkin L, Regan M, Salter J, Sotiriou C, Smith IE, Viale G, Zujewski JA, Hayes DF (2011) Assessment of ki67 in breast cancer: recommendations from the international ki67 in breast cancer working group. J Natl Cancer Inst 103: 1656-1664.

Ellis I, Dowsett M, Bartlett J, Walker R, Cooke T, Gullick W, Gusterson B, Mallon E, Lee P (2000) Recommendations for HER2 testing in the UK. J Clin Pathol 53: 890-892.

Faratian D, Kay C, Robson T, Campbell FM, Grant M, Rea D, Bartlett JMS (2009) Automated image analysis for high-throughput quantitative detection of ER and PR expression levels in large-scale clinical studies: the TEAM Trial Experience. Histopathology 55: 587-593.

Grambsch PM, Therneau TM (1994) Proportional hazards tests and diagnostics based on weighted residuals. Biometrika 81: 515-526.

Hammond MEH, Hayes DF, Dowsett M, Allred DC, Hagerty KL, Badve S, Fitzgibbons PL, Francis G, Goldstein NS, Hayes M, Hicks DG, Lester S, Love R, Mangu PB, McShane L, Miller K, Osborne CK, Paik S, Perlmutter J, Rhodes A, Sasano H, Schwartz JN, Sweep FCG, Taube S, Torlakovic EE, Valenstein P, Viale G, Visscher D, Wheeler T, Williams RB, Wittliff JL, Wolff AC. American Society of Clinical Oncology, College of American Pathologists (2010) American Society of Clinical Oncology/ College of American Pathologists guideline recommendations for immunohistochemical testing of estrogen and progesterone receptors in breast cancer (unabridged version). Arch Pathol Lab Med 134: e48-e72.
Harvey JM, Clark GM, Osborne CK, Allred DC (1999) Estrogen receptor status by immunohistochemistry is superior to the ligand-binding assay for predicting response to adjuvant endocrine therapy in breast cancer. J Clin Oncol 17: 1474-1481.

Haybittle JL, Blamey RW, Elston CW, Johnson J, Doyle PJ, Campbell FC, Nicholson RI, Griffiths K (1982) A prognostic index in primary breast cancer. Br J Cancer 45: 361-366.

Horwitz KB, McGuire WL (1975) Predicting response to endocrine therapy in human breast cancer: a hypothesis. Science 189: 726-727.

Horwitz KB, McGuire WL (1978) Estrogen control of progesterone receptor in human breast cancer. Correlation with nuclear processing of estrogen receptor. J Biol Chem 253: 2223-2228.

Jin H, Tu D, Zhao N, Shepherd LE, Goss PE (2012) Longer-term outcomes of letrozole versus placebo after 5 years of tamoxifen in the NCIC CTG MA.17 trial: analyses adjusting for treatment crossover. J Clin Oncol 30: 718-721.

Kyndi M, Sørensen FB, Knudsen H, Overgaard M, Nielsen HM, Andersen J, Overgaard J (2008) Tissue microarrays compared with whole sections and biochemical analyses. A subgroup analysis of DBCG 82 b\&c. Acta Oncol 47: 591-599.

Liu S, Chia S, Mehl E, Leung S, Rajput A, Cheang M, Nielsen T (2010) Progesterone receptor is a significant factor associated with clinical outcomes and effect of adjuvant tamoxifen therapy in breast cancer patients. Breast Cancer Res Treat 119: 53-61.

MacGrogan G, de Mascarel I, Sierankowski G, Mauriac L, Debled M, Durand M, De Lara CT, Avril A, Picot V, Mathoulin-Pélissier S (2005) Time for reappraisal of progesterone-receptor testing in breast cancer management. J Clin Oncol 23: 2870-2871; authorreply2871.

Mann GB, Fahey VD, Feleppa F, Buchanan MR (2005) Reliance on hormone receptor assays of surgical specimens may compromise outcome in patients with breast cancer. J Clin Oncol 23: 5148-5154.

Mohsin S, Weiss H, Havighurst T, Clark G, Berardo M, Roanh le D, To T, Qian Z, Love R, Allred D (2004) Progesterone receptor by immunohistochemistry and clinical outcome in breast cancer: a validation study. Mod Pathol 17: 1545-1554.

Mook S, Schmidt MK, Rutgers EJ, van de Velde AO, Visser O, Rutgers SM, Armstrong N, van't Veer LJ, Ravdin PM (2009) Calibration and discriminatory accuracy of prognosis calculation for breast cancer with the online Adjuvant! program: a hospital-based retrospective cohort study. Lancet Oncol 10: 1070-1076.

National Institute for Health, and Excellence (2009) CG80 Early and locally advanced breast cancer: full guideline (NICE).

Olivotto I, Truong P, Speers C, Bernstein V, Allan S, Kelly S, Lesperance M (2004) Time to stop progesterone receptor testing in breast cancer management. J Clin Oncol 22: 1769-1770.

Purdie CA, Baker L, Ashfield A, Chatterjee S, Jordan LB, Quinlan P, Adamson DJA, Dewar JA, Thompson AM (2010a) Increased mortality in HER2 positive, oestrogen receptor positive invasive breast cancer: a population-based study. Br J Cancer 103: 475-481.

Purdie CA, Jordan LB, McCullough JB, Edwards SL, Cunningham J, Walsh M, Grant A, Pratt N, Thompson AM (2010b) HER2 assessment on core biopsy specimens using monoclonal antibody CB11 accurately determines HER2 status in breast carcinoma. Histopathology 56: 702-707.

Rakha EA, El-Sayed ME, Lee AHS, Elston CW, Grainge MJ, Hodi Z, Blamey RW, Ellis IO (2008) Prognostic significance of Nottingham histologic grade in invasive breast carcinoma. J Clin Oncol 26: 3153-3158.

Ravdin P, Green S, Dorr T, McGuire W, Fabian C, Pugh R, Carter R, Rivkin S, Borst J, Belt R, Metch B, Osborne CK (1992) Prognostic significance of progesterone receptor levels in estrogen receptor-positive patients with metastatic breast cancer treated with tamoxifen: results of a prospective Southwest Oncology Group study. J Clin Oncol 10: 1284-1291.

SIGN (2007) S.I.G.N.Management of breast cancer in women. (SIGN Guideline No 84) 1-52.

Stendahl M, Ryden L, Nordenskjold B, Jonsson P, Landberg G, Jirstrom K (2006) High progesterone receptor expression correlates to the effect of adjuvant tamoxifen in premenopausal breast cancer patients. Clin Cancer Res 12: 4614-4618.

Sørlie T, Perou CM, Tibshirani R, Aas T, Geisler S, Johnsen H, Hastie T, Eisen MB, van de Rijn M, Jeffrey SS, Thorsen T, Quist H, Matese JC, Brown PO, Botstein D, Eystein Lønning P, Børresen-Dale AL (2001) Gene expression patterns of breast carcinomas distinguish tumor subclasses with clinical implications. Proc Natl Acad Sci USA 98: 10869-10874. 
Thakkar JP, Mehta DG (2011) A review of an unfavorable subset of breast cancer: estrogen receptor positive progesterone receptor negative. Oncologist 16: 276-285.

Thompson AM, Jordan LB, Quinlan P, Anderson E, Skene A, Dewar JA, Purdie CA. Breast Recurrence in Tissues Study Group (2010) Prospective comparison of switches in biomarker status between primary and recurrent breast cancer: the Breast Recurrence In Tissues Study (BRITS). Breast Cancer Res 12: R92.

Torhorst J, Bucher C, Kononen J, Haas P, Zuber M, Köchli OR, Mross F, Dieterich H, Moch H, Mihatsch M, Kallioniemi OP, Sauter G (2001) Tissue microarrays for rapid linking of molecular changes to clinical endpoints. Am J Pathol 159: 2249-2256.

van de Vijver MJ, He YD, van't Veer LJ, Dai H, Hart AAM, Voskuil DW, Schreiber GJ, Peterse JL, Roberts C, Marton MJ, Parrish M, Atsma D, Witteveen A, Glas A, Delahaye L, van der Velde T, Bartelink H, Rodenhuis S, Rutgers ET, Friend SH, Bernards R (2002) A gene-expression signature as a predictor of survival in breast cancer. N Engl J Med 347: 1999-2009.

van $t$ Veer LJ, Dai H, van de Vijver MJ, He YD, Hart AAM, Mao M, Peterse HL, van der Kooy K, Marton MJ, Witteveen AT, Schreiber GJ, Kerkhoven RM, Roberts C, Linsley PS, Bernards R, Friend SH (2002) Gene expression profiling predicts clinical outcome of breast cancer. Nature 415: 530-536.

Viale G, Regan M, Maiorano E, Mastropasqua M, Dell'Orto P, Rasmussen B, Raffoul J, Neven P, Orosz Z, Braye S, Ohlschlegel C, Thurlimann B,
Gelber R, Castiglione-Gertsch M, Price K, Goldhirsch A, Gusterson B, Coates A (2007) Prognostic and predictive value of centrally reviewed expression of estrogen and progesterone receptors in a randomized trial comparing letrozole and tamoxifen adjuvant therapy for postmenopausal early breast cancer: BIG 1-98. J Clin Oncol 25: 3846-3852.

Walker RA, Bartlett JMS, Dowsett M, Ellis IO, Hanby AM, Jasani B, Miller K, Pinder SE (2008) HER2 testing in the UK: further update to recommendations. J Clin Pathol 61: 818-824.

West M, Blanchette C, Dressman H, Huang E, Ishida S, Spang R, Zuzan H, Olson JA, Marks JR, Nevins JR (2001) Predicting the clinical status of human breast cancer by using gene expression profiles. Proc Natl Acad Sci USA 98: 11462-11467.

Yerushalmi R, Woods R, Ravdin PM, Hayes MM, Gelmon KA (2010) Ki67 in breast cancer: prognostic and predictive potential. Lancet Oncol 11: 174-183.

Yu WC, Leung BS, Gao YL (1981) Effects of 17 beta-estradiol on progesterone receptors and the uptake of thymidine in human breast cancer cell line CAMA-1. Cancer Res 41: 5004-5009.

This work is published under the standard license to publish agreement. After 12 months the work will become freely available and the license terms will switch to a Creative Commons AttributionNonCommercial-Share Alike 3.0 Unported License. 